\title{
Mapping the U.S. Production Network: Identifying Hub Industries
}

Sungki Hong, Economist

Hannah G. Shell, Senior Research Associate

Quihan Sun, Research Associate

P

roduction in advanced economies is increasingly complicated and interconnected across industries. The paths between industries-the production network-are important to understand because they can transmit negative shocks across firms. Recently, economists have started looking into individual sectoral shocks to explain aggregate economic fluctuations. ${ }^{1}$ This essay identifies industries that are important suppliers and buyers in the U.S. production network. A shock to an important supplier or buyer industry in the U.S. production network could have a contagion effect across the economy, causing an aggregate downturn.

\section{Heat Maps: A Picture of the U.S. Production Network}

Input-output tables describe how much each industry buys inputs from or sells inputs to other industries. Such tables permit us to study the production network of the U.S. economy. The figure shows heat maps constructed from input-output tables aggregated to 30 industries $^{2}$ : The columns in Panel A identify major suppliers, while the rows in Panel B identify major buyers.

Specifically, Panel A identifies which industries are the main suppliers of material inputs to other industries based on material cost shares. A material cost share is the material costs paid to a supplier industry (column) divided by the gross output of the buyer industry (row). To show relative importance, each share is color coded according to its share (percentage) of the given buyer industry's gross output: Higher shares are red, orange, or yellow, while lower shares are shades of darker blue. (Very small material shares are not colored.) Important suppliers, then, have many colored squares or squares in the upper part of the scale in their

\section{Input-Output Heat Maps}

A. Material Cost Shares (Important Suppliers)

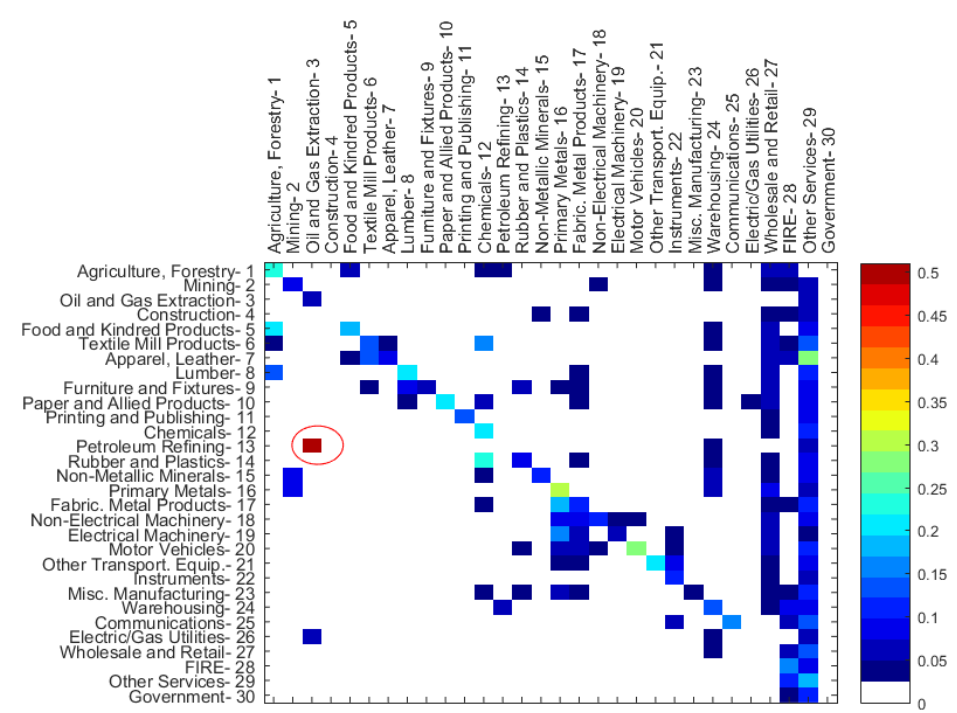

B. Output Cost Shares (Important Buyers)

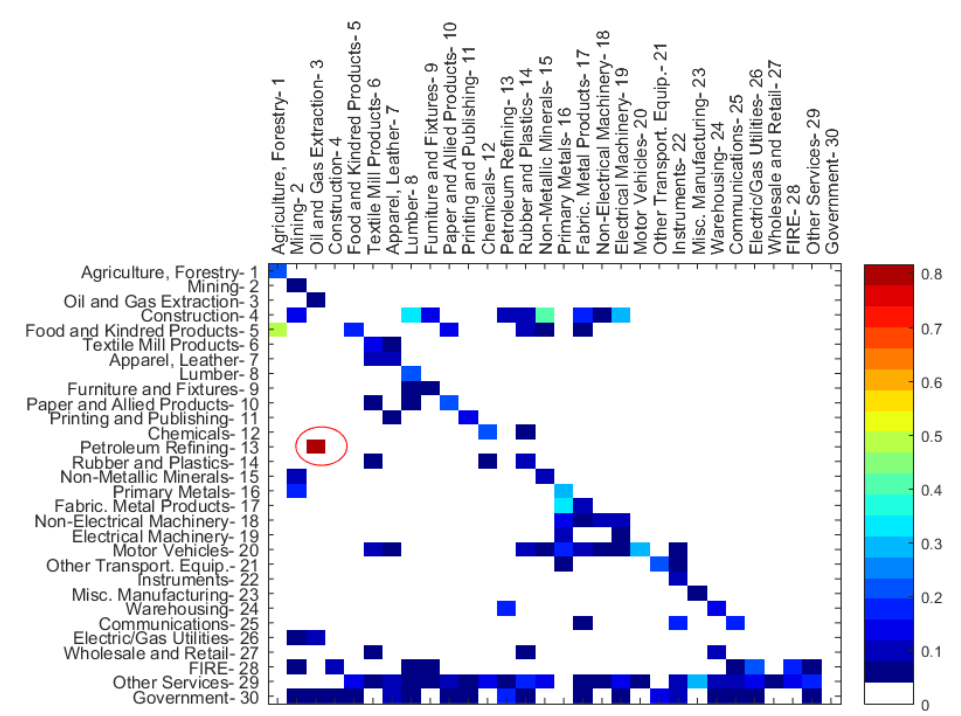

NOTE: A material cost share is the material costs paid to a supplier industry (column) divided by the gross output of the buyer industry (row). An output cost share is the cost of output sold to a buyer industry (row) divided by the gross output of the supplier industry (column). FIRE is finance, insurance, and real estate.

SOURCE: BEA and authors' calculations. 
column. For example, the many colored squares in the "other services" column show that many industries rely on inputs from the other services industry. The circled red square on the left side of Panel A shows that the oil and gas extraction industry supplies material inputs equal to 50 percent of the gross output of the petroleum refining industry. The many colored squares along the diagonal imply that many industries supply materials to firms within their own industry.

\section{Identifying key suppliers and buyers could help identify the cause of certain economic downturns.}

Panel B identifies which industries are the main buyers of output from other industries based on output cost shares. An output cost share is the cost of output sold to a buyer industry (row) divided by the gross output of the supplier industry (column). The color coding of the squares is the same, but with a different range for the scale. Important buyers, then, have many colored squares or squares in the upper range of the scale in their row. (Columns with few or no colored squares are either diversified across purchasing industries or sell most of their output directly to the consumer). For example, the many colored squares in the other services and government rows mean that these industries are important buyer industries of many supplier industries. In contrast, the circled red square on the left side of Panel B shows that the petroleum refining industry is the major buyer for the oil and gas extraction industry. Once again, the prominent diagonal line implies that many industries buy materials from firms within the same industry.
These heat maps identify the industries in the United States where industry-specific shocks could translate to aggregate downturns. For example, the construction industry has several colored squares in its rows and columns on the heat maps-it is both an important supplier and an important buyer. Based on Panel B, if a negative shock causes the construction industry to restrict activity, the lumber and non-metallic minerals industries (the light blue squares in row 4 , columns 8 and 15 , respectively) could lose up to 40 percent of their customer base, likely causing layoffs and firm closures in these partner industries. This scenario is exactly what played out in the 2007-09 recession, when the construction industry experienced a huge shock.

\section{Conclusion}

A highly integrated production process complicates the transmission of shocks across industries. This essay identifies certain important buyers and sellers using BEA input-output tables. Understanding which industries are hubs in the production networks can help economists better understand, and possibly predict, the cause of certain economic downturns.

\section{Notes}

1 Atalay, Enghin. "How Important Are Sectoral Shocks?" American Economic Journal: Macroeconomics, 2017, 9(4).

2 We start with the 71 Bureau of Economic Analysis (BEA) industry input-output tables (specifically, use tables) and aggregate to 30 industries using the crosswalk published in Atalay (2017). 